\title{
Histone H1 subtype-specific consensus elements mediate cell cycle-regulated transcription in vitro
}

\author{
Franca La Bella, Paola Gallinari, John McKinney, and Nathaniel Heintz ${ }^{1}$ \\ Howard Hughes Medical Institute, Laboratory of Molecular Biology, The Rockefeller University, New York, New York 10021 \\ USA
}

\begin{abstract}
In this study we used nuclear extracts from centrifugally elutriated cell populations to study histone $\mathrm{H1}$ transcriptional regulation during the cell cycle. Analysis of mutations within the H1 promoter establish that both of the $\mathrm{H} 1$ subtype-specific consensus elements participate in induction of transcription upon entry into $S$ phase. The DNA binding activity of H1TF2, which specifically interacts with the H1 proximal subtype-specific element, is increased in S-phase nuclear extracts, whereas no increase in DNA binding is observed for the H1 distal subtype-specific DNA transcription factor H1TF1 or the H2b subtype-specific factor OTF1. These data strongly support the idea that histone gene subtype-specific transcription factors are important for S-phasedependent expression of histone genes. Further studies of these factors will be important for increased understanding of the transition from $G_{1}$ to $S$ phase of the mammalian cell cycle.
\end{abstract}

[Key Words: Cell cycle; histone genes; in vitro transcription; centrifugal elutriation; transcription factors]

Received July 11, 1989; revised version accepted September 7, 1989.

The transition from $G_{1}$ to $S$ phase in the eukaryotic cell cycle results in the activation of chromosomal DNA synthesis and the increased production of a variety of activities required for synthesis or packaging of nascent DNA. The synthesis of most histone proteins is dramatically induced at this time (Robbins and Borum 1967), because of both increased rates of transcription of the individual histone genes and accelerated post-transcriptional histone mRNA accumulation (Heintz et al. 1983; Sittman et al. 1983). Recent studies of the mechanisms regulating histone gene transcription demonstrated that promoter proximal DNA sequences (Artishevsky et al. 1987; Dalton and Wells 1988a; La Bella et al. 1988) and their cognate transcription factors (Fletcher et al. 1987; Dalton and Wells 1988b) are crucial for increased transcription during $S$ phase. It is our belief that a detailed knowledge of these proteins and their changing activities during $S$ phase can lead to fundamental advances in our understanding of the cell cycle.

The most specific information concerning the regulation of histone gene expression during $S$ phase has been obtained by analysis of histone $\mathrm{H} 2 \mathrm{~b}$ gene expression. We have demonstrated that a very highly conserved subtype-specific consensus element, containing the core octanucleotide ATTTGCAT and positioned immediately upstream from the TATA element, mediates cell-cycle regulation of $\mathrm{H} 2 \mathrm{~b}$ transcription (La Bella et al. 1988). The transcription factor that specifically interacts with this regulatory element has been purified and characterized

${ }^{1}$ Corresponding author.
(Fletcher et al. 1987), although the precise mechanism by which this factor contributes to the $S$-phase induction of $\mathrm{H} 2 \mathrm{~b}$ transcription is not yet known. The $\mathrm{H} 2 \mathrm{~b}$ cell-cycle regulatory element is not present in genes encoding other histone subtypes. However, comparison of the $\mathrm{H} 4, \mathrm{H} 2 \mathrm{~b}$, and $\mathrm{H} 1$ promoters reveals that each promoter contains a highly conserved subtype-specific consensus element adjacent to the TATA element. Proteins that interact with each of these elements have been identified and shown to be distinct (Dailey et al. 1986; Fletcher et al.1987; Gallinari et al. 1989). On the basis of these results, we have proposed that the subtype-specific consensus elements are critical cell-cycle regulatory sequences and that induction of the $\mathrm{H} 4, \mathrm{H} 2 \mathrm{~b}$, and $\mathrm{Hl}$ histone genes during $\mathrm{S}$ phase is the result of coordinate activation of these different proteins. To directly test the validity of this idea and to gain further insight into the regulation of subtype-specific factors during $S$ phase, we developed an improved methodology for analysis of cellcycle regulation in vitro and employed it in the analysis of histone $\mathrm{H} 1$ transcriptional regulation.

The $\mathrm{Hl}$ promoter is particularly interesting because it contains two subtype-specific consensus elements: a proximal subtype-specific element adjacent to the TATA box and a distal $\mathrm{Hl}$ subtype-specific element, the AC box, $\sim 100$ bp upstream from the cap site. The primary sequence, position, and orientation of these elements are very highly conserved between replication-dependent $\mathrm{H} 1$ genes in different species. Our laboratory (Gallinari et al. 1989) has characterized a $47-\mathrm{kD}$ protein (H1TF2), which protects the entire proximal subtype- 
specific element from digestion with DNase and requires the CCAAT core motif within the conserved domain for interaction with the $\mathrm{Hl}$ promoter. Dalton and Wells (1988a) have demonstrated that the AC box is essential, if not sufficient, for $\mathrm{Hl}$ transcriptional regulation in vivo. They have also reported (Dalton and Wells 1988b) that a factor interacting with the $\mathrm{Hl} \mathrm{AC}$ box in vitro is more active in specific DNA binding when assayed in extracts of S-phase cells than in cells blocked with aphidicolin at the $\mathrm{G}_{1} / \mathrm{S}$-phase boundary. The demonstration that both of the $\mathrm{H} 1$ subtype-specific elements contribute to transcription in extracts from unsynchronized HeLa cells (Gallinari et al. 1989) suggested that a direct comparison of their transcriptional activity in synchronized cell extracts should yield important information.

In this study we employed centrifugal elutriation for preparation of transcription extracts from relatively homogeneous populations of cells in specific phases of the cell cycle. The centrifugal elutriation procedure employed in this work does not involve exposure of the cells to drugs and yields highly reproducible regulation of histone gene transcription as a function of position in the cell cycle. We employed this system to study the role of the $\mathrm{H} 1$ subtype-specific consensus elements in transcriptional regulation during the cell cycle. Our results confirm the prediction from in vivo studies of $\mathrm{H} 2 \mathrm{~b}$ regulation (La Bella et al. 1988) that the proximal H1 subtype-specific element is an important determinant of $\mathrm{S}$-phase-specific $\mathrm{H} 1$ transcription. They also indicate, in agreement with the studies of Dalton and Wells (1988a), that the $\mathrm{H} 1$ distal subtype-specific sequence, the AC box, participates in cell-cycle control.

\section{Results and discussion}

The proximal H1 subtype-specific consensus element is an important determinant of histone $\mathrm{H1}$ cell cycleregulated transcription in vitro

The initial aim of this study was to develop an in vitro system for analysis of mechanisms regulating gene expression during the cell cycle that did not involve cell synchronization by drug treatments or growth arrest by serum or nutrient deprivation. To achieve this aim, we employed centrifugal elutriation (Lindahl 1986) to obtain large populations of cells at different stages of the cell cycle (Meistrich et al. 1977; Hann et al. 1985). A significant advantage of this procedure over those employed previously (Heintz and Roeder 1984) is that cells can be pumped into the rotor under normal growth conditions and snap-cooled within $30 \mathrm{sec}$ by washing with ice-cold buffer. Furthermore, if the elutriation conditions are uniform from experiment to experiment (see Materials and methods), the elutriation procedure yields reproducible cell populations. For these experiments we chose to collect cells in four different fractions: $G_{1} / S_{1}$, $S_{1}$, and $G_{2}$. As shown in Figure 1 , fluorescein-activated cell sorter (FACS) analysis of the DNA content of cells in these four fractions indicates that the $G_{1}$ population is $>95 \% \mathrm{G}_{1}$, the S-phase fraction has $>85 \%$ S-phase cells, and the $G_{2}$ cell population is slightly more contaminated with S-phase cells $(\sim 20 \%$ S-phase cells). A fraction containing approximately equal numbers of $G_{1}$ and S-phase cells was also collected to assess whether the $G_{1}$ cell population may contain specific inhibitors of S-phase-specific regulatory factors.

The experiment shown in Figure 1 was designed to directly test our predication, based on analysis of the histone $\mathrm{H} 2 \mathrm{~b}$ promoter in vivo, that the $\mathrm{H} 1$ subtype-specific consensus element adjacent to the TATA box would be directly involved in cell-cycle control (La Bella et al. 1988). Thus, we transcribed both the wild-type H1 promoter/chloramphenicol acetyltransferase (CAT) fusion plasmid $(-180)$ and the same $\mathrm{Hl}$ promoter/CAT fusion containing a point mutation within the $\mathrm{Hl}$ proximal subtype-specific element (D-10) (Gallinari et al. 1989), using extracts from the four cell populations discussed above. These transcription assays were performed in duplicate and in the presence of an internal control template, as described previously (Gallinari et al. 1989). The first important point to be made is that transcription of the internal control gene does not vary significantly between the extracts. Because this gene is driven by a truncated histone $\mathrm{H} 4$ promoter containing only the TATA box and cap site, its uniform transcription indicates that the activity of the general transcription factors is relatively constant in the four different extracts. This statement is supported further by the similar levels of transcription from vector sequences that map as larger protected fragments running as a smear at the top of each lane. (It should be noted that the discrete band observed in this area of the gel in reactions programmed by the D-10 DNA templates presumably results from S1 cleavage at the site of the single point mismatch between the probe and these randomly initiated transcripts).

The second and most important point to be made from Figure 1 is that the $\mathrm{Hl}$ proximal subtype-specific element is used preferentially in extracts from S-phase HeLa cells. Thus, in nuclear extracts prepared from the $\mathrm{G}_{1}$ cell populations, the wild-type and D-10 mutant $\mathrm{Hl}$ promoters are transcribed with equal efficiency and approximately as well as the internal control template DNA. In $G_{1}$ extracts, there is essentially no effect of inactivating the proximal subtype-specific consensus element on the efficiency of transcription in vitro. However, when these two template DNAs are used to program transcription in extracts from S-phase cells, there is a dramatic difference in the efficiency with which they are utilized. This result demonstrates that the $\mathrm{Hl}$ proximal subtype-specific consensus element is active preferentially in S-phase nuclear extracts. Further support for this conclusion is presented in Table 1 , in which quantitation of results from five separate sets of cellcycle extracts is shown.

Inspection of the results of transcription of these template DNAs in the $G_{1} / S$ and $G_{2}$ extracts yields additional information. In both of these types of extract, the level of transcription is roughly proportional to the fraction of cells in the population that have an S-phase DNA con- 

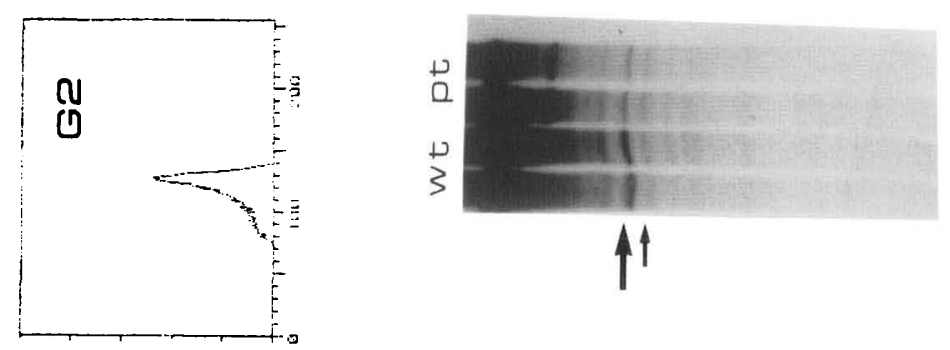

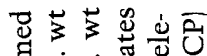
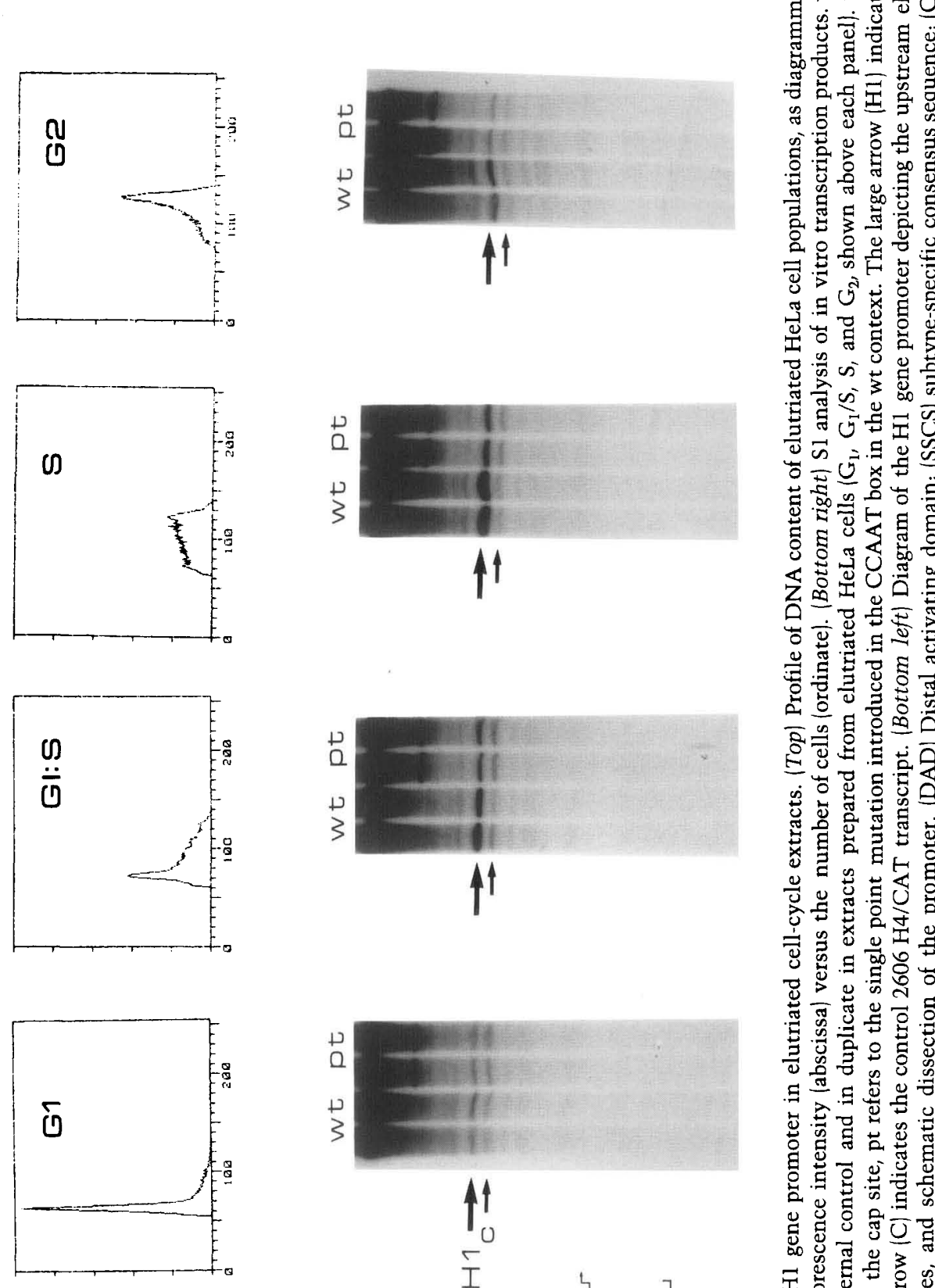

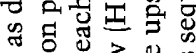

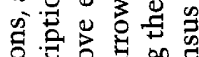

苟苟

응 矛矛

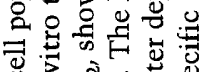

ச

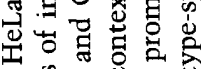

造的范范

焉焉出焉焉

的部跑

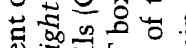

业年

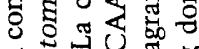

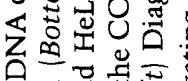

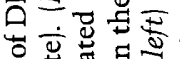

$\pi$

焉总导

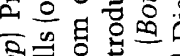

웡

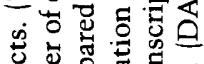

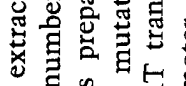

氙芯芯芯

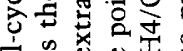

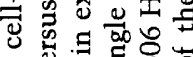

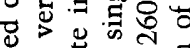

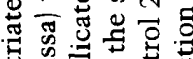

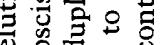

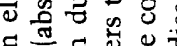

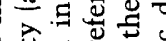

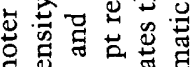

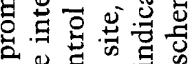

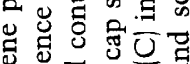

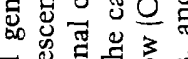

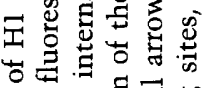

I

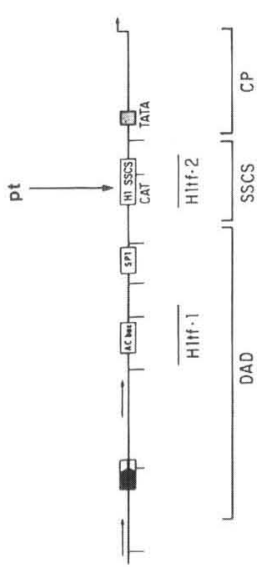

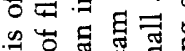

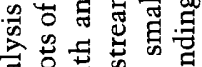

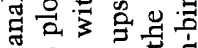

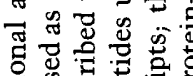

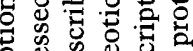

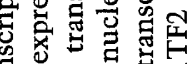

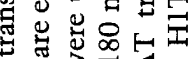

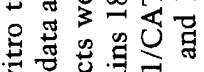

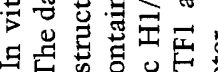

-

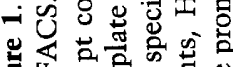

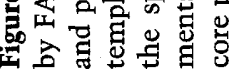


Table 1. Quantitation of transcriptional and DNA binding activities of histone-specific transcription factors during the cell cycle

\begin{tabular}{|c|c|c|c|c|c|c|}
\hline \multirow[b]{2}{*}{ Experiment } & \multicolumn{3}{|c|}{$\begin{array}{l}\text { Transcriptional induction } \\
\left.\text { (S extract } / \mathrm{G}_{1} \text { extract }\right)\end{array}$} & \multicolumn{3}{|c|}{$\begin{array}{l}\text { DNA-binding activity } \\
\left.\text { (S extract } / \mathrm{G}_{1} \text { extract }\right)\end{array}$} \\
\hline & W.T. & -85 & $\mathrm{D}-10$ & HlTF1 & H1TF2 & OTF1 \\
\hline 1 & 11.0 & - & 3.3 & 1.2 & 5.2 & 1.0 \\
\hline 2 & 2.5 & - & 1.3 & 1.0 & 2.0 & 1.0 \\
\hline 3 & 12.0 & 7.8 & 7.0 & 0.8 & 3.4 & 0.9 \\
\hline 4 & 2.9 & 1.9 & 1.7 & 1.1 & 2.8 & 0.8 \\
\hline 5 & 13.0 & 5.7 & 5.4 & - & - & - \\
\hline
\end{tabular}

Transcriptional induction data of experiments 1 and 3 are shown, respectively, in Figs. 1 and 2. DNA binding activity data of experiment 3 are shown in Fig. 3.

tent. This suggests that the presence of either $G_{1}$ or $G_{2}$ cells in the original fraction of cells from which the extract is prepared does not inhibit the utilization of the proximal subtype-specific consensus element by factors derived from the S-phase cells present in that population. Therefore, it is evident that no dominant inhibitory activities from $G_{1}$ or $G_{2}$ cells are present in the mixed cell extracts.

The distal H1 subtype-specific consensus element, the $A C$ box, is also involved in cell-cycle control in vitro

Previous in vivo (Dalton and Wells 1988a) and in vitro (Dalton and Wells 1988b) experiments have suggested that the H1 AC box may also be important for regulation of $\mathrm{H} 1$ transcription during the cell cycle. Although the experiment shown in Figure 1 identifies the proximal subtype-specific element as an important cell-cycle regulatory element, it also suggests that other sequences in the H1 promoter may contribute to S-phase transcriptional induction. Thus, although maximal induction of H1 transcription between the $\mathrm{G}_{1}$ - and S-phase extracts requires the proximal subtype-specific element, transcription of the mutant template DNA remains induced relative to the internal control DNA template. As we demonstrated previously, the D-10 mutation results in a 100-fold decrease in H1TF2 binding (Gallinari et al. 1989|, it seemed unlikely that this consistently reproducible result was the result of residual activity of the proximal subtype-specific consensus element. Therefore, we decided to investigate the role of the $\mathrm{Hl}$ distal subtype-specific element in transcription of the $\mathrm{Hl}$ promoter in the elutriated cell-cycle extracts.

An experiment addressing this issue is presented in Figure 2. The three templates used in this assay were $\mathrm{H} 1$ promoter/CAT gene fusions containing sequences to -112 bp upstream from the $\mathrm{Hl}$ cap site, to $-85 \mathrm{bp}$ in the promoter, which excises the $\mathrm{H} 1 \mathrm{AC}$ box, and the D-10 point mutant template (diagrammed in Fig. 2). Because the extracts employed in this assay had been characterized previously in an experiment similar to that shown in Figure 1 and because the duplicate reactions were very reproducible, no internal control was included in these reactions. This results in much less background in the assay and allows more accurate quantitation of the data. As shown in Figure 2, all three of these tem- plate DNAs are transcribed with equal efficiency in the $G_{1}$ nuclear extract, indicating that neither of the subtype-specific elements contributes significantly to transcription in that extract. Transcription of all of these templates is significantly higher in the S-phase nuclear extract. Deletion of the AC box and inactivation of the $\mathrm{H} 1$ proximal subtype-specific element each result in an approximately equal loss in S-phase inducibility of the $\mathrm{Hl}$ promoter, suggesting that both of these elements are important for maximum S-phase induction of $\mathrm{H} 1$ transcription in vitro. Comparison of several assays of this type consistently supported this conclusion (see Table 1), although the relative contribution of the $\mathrm{H} 1$ proximal element was sometimes greater than that of the distal element. These results confirm the previous studies of Wells and colleagues (Dalton and Wells 1988a, b), suggesting a role for the $\mathrm{AC}$ box in cell-cycle regulation, and demonstrate that both of the $\mathrm{H} 1$ subtype-specific elements are involved in $\mathrm{Hl}$ transcriptional induction upon entry into $S$ phase. These data, taken together with our previous results of $\mathrm{H} 2 \mathrm{~b}$ transcriptional regulation in vivo (La Bella et al. 1988), establish that the S-phase inducibility of histone gene expression is due to subtypespecific control elements that are utilized in cycling cell populations only during $\mathrm{S}$ phase.

Binding of subtype-specific transcription factors to the $\mathrm{H} 2 \mathrm{~b}$ and $\mathrm{H} 1$ histone promoters in cell-cycle nuclear extracts

The transcription assays presented above establish that the cell-cycle control of histone gene transcription can be mimicked in extracts from centrifugally elutriated HeLa cell populations. Because the cell-cycle regulatory activity of the $\mathrm{H} 2 \mathrm{~b}$ (Fletcher et al. 1987) and $\mathrm{H} 1$ (this study) subtype-specific sequences have been reproduced in vitro, it was important to determine whether the DNA binding activities of the factors interacting with these elements change during the cell cycle. This seemed particularly important given the apparently conflicting results obtained in studies of the H2b subtypespecific factor OTF1-binding activity in extracts from serum-stimulated Chinese hamster lung fibroblasts (Ito et al. 1989) and in extracts of chicken erythroid cells synchronized by a single treatment with aphidicolin (Dalton and Wells 1988b). Because neither of these pre- 


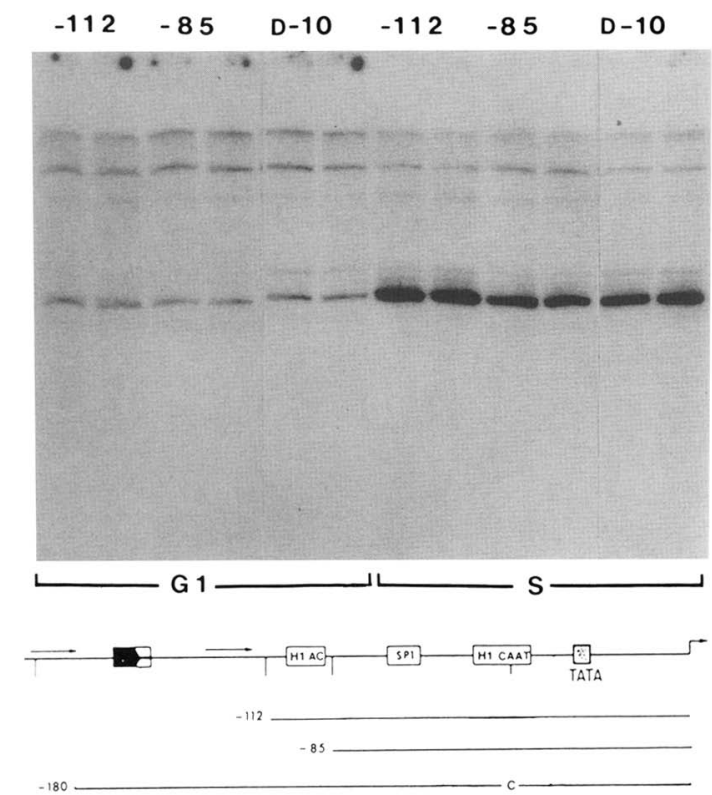

Figure 2. In vitro transcription of $\mathrm{Hl}$ gene promoter mutants in $G_{1}$ and S-phase extracts. $S 1$ analysis of in vitro transcription products. In extracts prepared from elutriated HeLa cells $\left\langle G_{1}\right.$ and S), $200 \mathrm{ng}$ of each template was transcribed in duplicate. Diagrams of the deletion mutant $(-112$ and -85$)$ and of the point mutant (D-10) used are shown at bottom. D-10 is identical to the pt template of Fig. 1.

vious studies demonstrated by functional assays of the extracts that histone gene transcriptional regulation is reproduced in the extracts and because both studies employed less physiologic synchronization procedures, we decided to re-examine this issue in the elutriated cell extracts.

The experiment shown in Figure 3 employed the gel mobility shift assay to determine the levels of H1TF1, H1TF2 (Gallinari et al. 1989), and OTF1 (Fletcher et al. 1987) in the $G_{1}$ and $S$-phase nuclear extracts used to demonstrate regulated $\mathrm{Hl}$ transcription (Fig. 1). Each lane of the assay contained $5 \mu \mathrm{g}$ of crude nuclear extract and $1 \mathrm{ng}$ of labeled probe corresponding to one of the three subtype-specific binding sites. The amount of total oligonucleotide competitor per reaction was held constant in the reactions of each panel by varying the ratio of specific to nonspecific competitor (Gallinari et al. 1989) as the amount of specific oligonucleotide was titrated. Under these conditions, the assays were reproducible and within the linear range with respect to titration of the nuclear extract (data not shown), allowing us to compare the relative level of each of these DNAbinding activities in the $G_{1}$ and S-phase crude nuclear extracts.

As is evident from the data presented in Figure 3, the results of this assay demonstrate that neither H1TF1 binding to the $\mathrm{H} 1 \mathrm{AC}$ box nor OTF1 binding to the $\mathrm{H} 2 \mathrm{~b}$ octamer element changes during the transition from $\mathrm{G}_{1}$ to S-phase. However, the activity of H1TF2 binding to the $\mathrm{H} 1$ proximal subtype-specific consensus element significantly and reproducibly increases in the S-phase nuclear extract. Having performed this assay using four separate sets of elutriated nuclear extracts and having assayed several different nuclear DNA-binding proteins in these extracts, we have consistently observed that only the binding of H1TF2 is specifically increased in the S-phase nuclear extracts (see Table 1 for H1TF1, HITF2, and OTF1 data). Thus, we conclude that of the three proteins that appear to be involved in the S-phase induction of histone gene expression, only H1TF2 has been demonstrated to vary its DNA binding activity during the cell cycle.

These results are in contrast to the previous study of Dalton and Wells (1988b), as we have failed to detect the dramatic increase of DNA binding activity to the $\mathrm{Hl} \mathrm{AC}$ box observed in the aphidicolin-synchronized chicken erythroid cells. However, our data do agree with their assertion that OTF1-binding activity does not change as the cells are released into $S$ phase. The reasons for this discrepancy are not known, although differences in the cells used, the synchronization protocol, and the prefractionation step included in the experiment of Dalton and Wells may all be contributing factors. The results of both the transcription and DNA-binding assay presented would suggest that changes in HITFl binding to the AC box may not be required for cell-cycle regulation, as hypothesized by Dalton and Wells. In contrast, our results indicate that changes in HITF2 binding to the proximal Hl subtype-specific element may play a role in cellcycle regulation.

The conclusion that OTFl DNA-binding activity does not vary during the cell cycle supports our previous studies in the nuclear extracts from thymidine- and aphidicolin-synchronized HeLa cells (C. Fletcher, unpubl.) and contradicts the conclusions of Maxson and colleagues (Ito et al. 1989) derived from experiments using extracts from serum-stimulated Chinese hamster lung fibroblasts. One obvious explanation for this difference is that the serum-stimulation protocol cannot be used to assess mechanisms operative in cycling cell populations. Rather, it is more appropriately used as a measure of growth regulation of transcription factor activity upon entry into the cell cycle following stimulation of quiescent cells with serum. One might easily imagine, for example, that OTFl-binding activity is increased upon refeeding of serum-starved cells, but that OTF1 DNA binding is not regulated in a cycling cell population.

\section{Induction of H1TF1, H1TF2, and OTF1 after serum stimulation of NIH-3T3 cells}

To determine whether the activities of the $\mathrm{H} 1$ and $\mathrm{H} 2 \mathrm{~b}$ subtype-specific DNA binding proteins are stimulated upon re-entry into the cell cycle from quiescence, the levels of these factors were measured by the mobility shift assays in extracts from serum-arrested and serumstimulated NIH-3T3 cells. Furthermore, to assess whether any observed change in DNA binding activity 
resulted from entry into $S$ phase, the stimulated cell population was split in half; one-half was treated for the duration of the experiment with aphidicolin. Because the serum-stimulation protocol results in a rather robust increase in total cell protein, the extracts were normalized to a single final protein concentration during preparation and equal amounts of each extract were assayed, as in Figure 3.

As shown in Figure 4A, $\left[{ }^{3} \mathrm{H}\right]$ thymidine incorporation assays and FACS analysis of cells treated in parallel with the plates used for preparation of the nuclear extracts indicate that the serum arrest protocol yields relatively well-synchronized cell populations, although they become somewhat asynchronous as the time after serum stimulation increases. Thus, we have not observed that the cells pass through $S$ phase with enough synchrony to monitor a decrease in $\left[{ }^{3} \mathrm{H}\right]$ thymidine incorporation between $\mathrm{T}=18$ and $\mathrm{T}=24 \mathrm{hr}$ post-stimulation. It is also apparent from these data that treatment with aphidicolin effectively blocks progression of the stimulated cells into $\mathrm{S}$ phase.

In contrast to the result obtained in centrifugally elutriated cell-cycle extracts, the specific DNA binding activity of each of these factors increases in the $T=18$ serum-stimulated nuclear extracts relative to the extract prepared from cells harvested only $2 \mathrm{hr}$ after serum addition (Fig. 4B). The level of induction of the $\mathrm{Hl}$ proximal subtype-specific factor H1TF2 ( 3-fold) is consistently greater than those of the $\mathrm{H} 2 \mathrm{~b}$ subtype-specific factor OTF1 ( 1.7-fold) and the $\mathrm{H} 1$ distal subtype-specific factor HlTF $1(\sim 1.5$-fold). It is particularly important to note that the induction of these activities following serum stimulation of NIH-3T3 cells is not influenced by the presence of aphidicolin. Because this drug effectively blocks progress of the cells into $\mathrm{S}$ phase, the increase observed in this type of protocol is most likely because of growth regulation of the abundance of these transcription factors upon entry into the cell cycle. This analysis suggests, therefore, that the serum-stimulation protocol cannot be effectively employed to analyze mechanisms operating on entry into $S$ phase in cycling cell populations. The data available thus far indicate that the activity of the histone subtype-specific transcription factors and perhaps many other unrelated trans-activating proteins, is subject to growth regulation, but that only a subset of these proteins will show fluctuations of DNA binding activity as logarithmically growing cells progress through the cell cycle.

\section{A model for the induction of S-phase-specific macromolecular synthesis}

The major result presented in this study is that histone $\mathrm{H} 1$ gene expression during $\mathrm{S}$ phase is mediated by the two H1 subtype-specific consensus elements. In extracts from centrifugally elutriated cell populations, we consistently observe a role for the proximal subtype-specific element in mediating S-phase-specific transcription and a parallel change in the DNA binding activity of its cognate transcription factor H1TF2. The H1 distal subtypespecific sequence, the AC box, also participates in cellcycle-regulated $\mathrm{Hl}$ transcription, as reported previously (Dalton and Wells 1988a,b), although our experiments do not reveal a change in DNA binding activity of H1TFl during the cell cycle. Thus, this study confirms the prediction, on the basis of our previous analysis of histone H2b gene regulation (La Bella et al. 1988), that subtype-specific consensus elements mediate the cell cycle-regulated transcription of histone genes, thus lending credence to the idea that H4TF2 (Dailey et al. 1988) may also be activated on entry into $S$ phase. The fact that each of the subtype-specific transcription

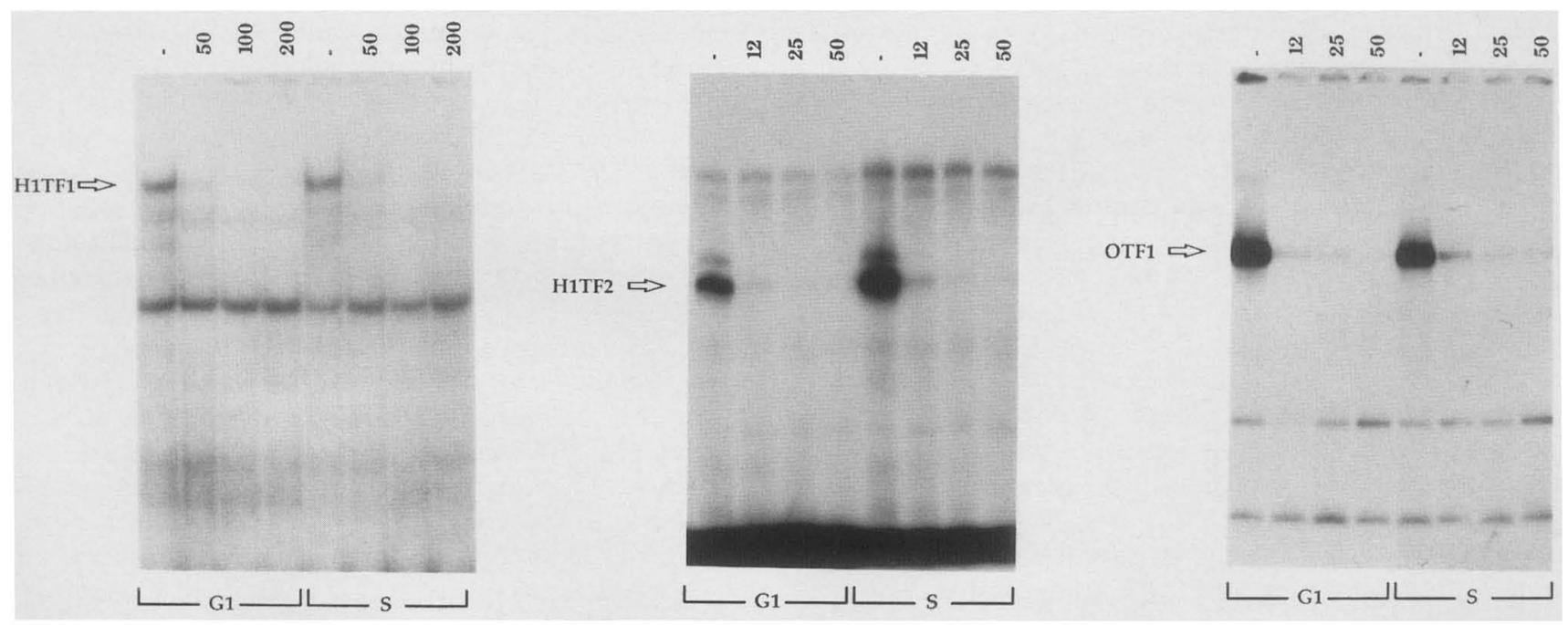

Figure 3. Binding activities of histone-specific transcription factors during the cell cycle. Gel shift analysis of H1TF1, H1TF2, and OTF1 in elutriated HeLa cell extracts $\left(G_{1}\right.$ and S). One nanogram of each end-labeled oligonucleotide was tested by competition with increasing amounts of cold specific oligonucleotides (amounts expressed in nanograms above each lane). The total amount of oligonucleotide competitors was held constant at a molar excess of 200-fold for H1TF1 and 50-fold for both H1TF2 and OTF1, varying the quantity of nonspecific competitor. Five micrograms of either $G_{1}-$ or S-phase extract was used in the assay. Specific DNA-protein complexes are indicated. 

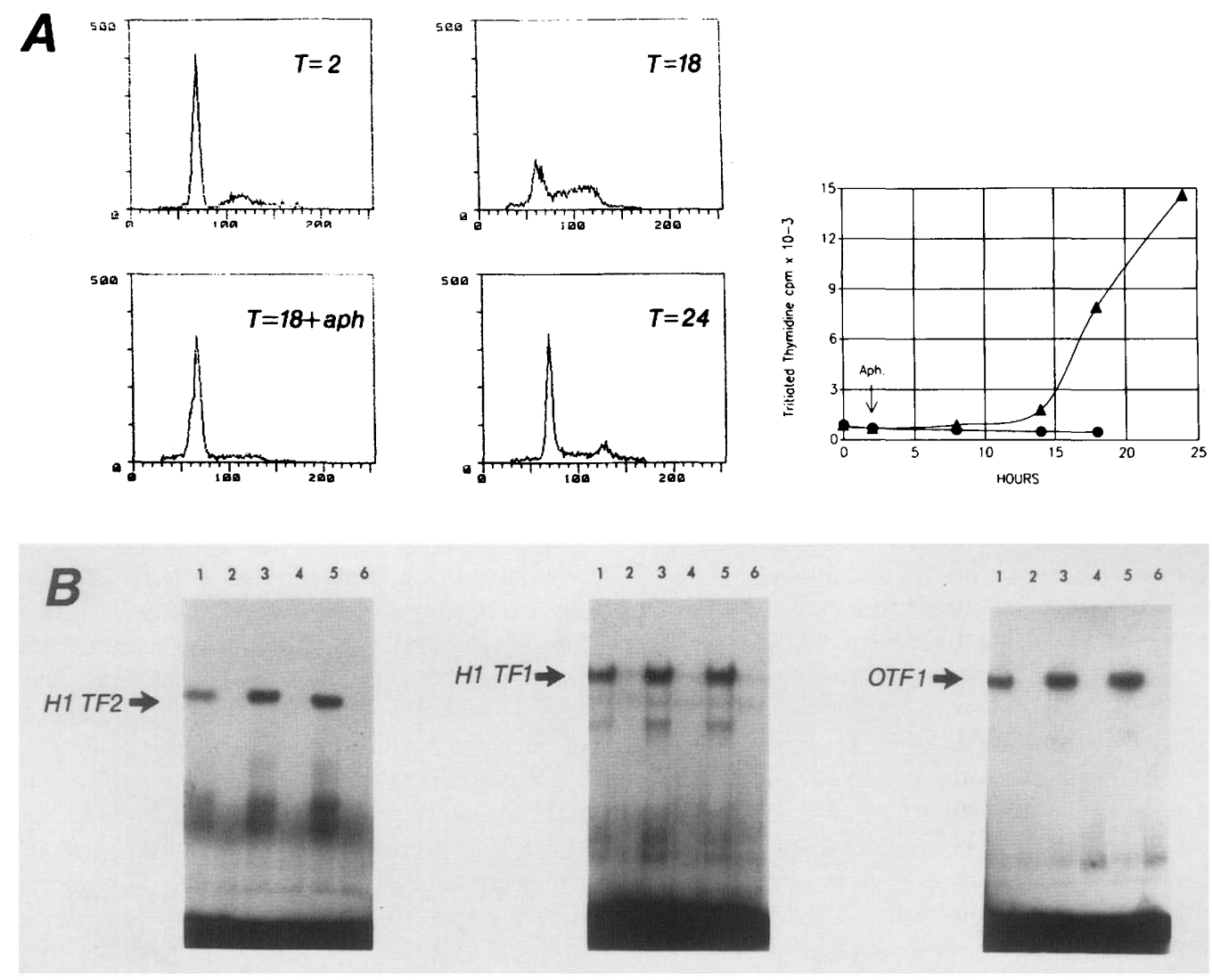

Figure 4. Binding activities of histone-specific transcription factors in extracts from serum-synchronized NIH-3T3 cells. (A) FACS profile of DNA content and curve of $\left[{ }^{3} \mathrm{H}\right]$ thymidine incorporation. $(\Delta)$ Absence of aphidicolin; $(O)$ presence of $5 \mu \mathrm{g} / \mathrm{ml}$ aphidicolin. $(B)$ Gel shift analysis of HITF1, H1TF2, and OTF1 in extracts from serum-starved cells $(t=2$, lanes 1 and 2$)$, released cells $(t=18$, lanes 3 and 4), and aphidicolin-arrested cells $(t=18+$ aph, lanes 5 and 6$)$. Either nonspecific (lanes 1,3 , and 5$)$ or specific (lanes 2, 4, and 6) oligonucleotide competitors were added to the binding reaction mixes at a molar excess of 50 -fold. Specific DNA-protein complexes are indicated by arrows.

factors is distinct is highly provocative and has implications for the analysis of general regulatory circuits that operate during the transition from $G_{1}$ to $S$ phase.

Our concept of the transition from $G_{1}$ to $S$ phase in mammalian cells is consistent with previous ideas concerning the cell cycle (see Lee and Nurse 1988). Thus, we imagine that a variety of important and interacting biochemical pathways converge at the restriction point (Pledger et al. 1977; Zetterberg and Larsson 1985) late in $\mathrm{G}_{1}$ to initiate a discrete biochemical cascade that ultimately results in the activation of S-phase-specific events (see Fig. 5). The number of regulatory events that occur between the commitment to enter $\mathrm{S}$ phase and the initiation of DNA synthesis is not known, although genetic evidence in yeast suggest that there may be several such steps prior to S phase (Lee and Nurse 1988). Our studies are directed toward understanding the mechanism of induction of histone gene transcription, which we consider to be the last step of this cascade. It is possible that the mechanism that activates the histone subtype-specific transcription factors during the $\mathrm{G}_{1} / \mathrm{S}$-phase transition also activates proteins regulating chromosomal DNA synthesis and transcription of other Sphase-specific genes. Additionally, the histone gene sub- type-specific factors, may be directly involved in other $S$-phase-specific macromolecular synthesis events. For example, it has been demonstrated that the $\mathrm{H} 2 \mathrm{~b}$ factor OTFl can participate in adenovirus DNA replication in vitro (O'Neill et al. 1988). A role for this protein in chromosomal DNA synthesis might be anticipated. Therefore, we imagine that there is a single regulatory event at the onset of $S$ phase that coordinately activates a relatively small number of trans-acting factors responsible for S-phase-specific synthetic events.

We have proposed that the histone subtype-specific transcription factors described herein are activated during the $\mathrm{G}_{1} / \mathrm{S}$-phase transition; therefore, our immediate goal is to determine the biochemical basis for this activation. This analysis will be greatly facilitated by use of centrifugal elutriation, which now allows us to prepare large-scale extracts from cells synchronized at various points in the cell cycle. We have considered three possible mechanisms for the activation of these factors. The first is that a cell cycle-regulated enzyme covalently modifies these factors, thereby modulating their activity. The obvious guess for such a modification is phosphorylation. However, we have been unsuccessful in attempts to inactivate H1TF1, H1TF2, and 
OTF1 with both potato acid phosphatase and calf intestine phosphatase under a variety of conditions that are effective for inactivation of other DNA-binding proteins (data not shown). Although these negative results are not entirely persuasive, a number of other biochemical properties of these factors suggest that we should consider noncovalent mechanisms for S-phase induction of these activities.

A second possibility that we find particularly attractive is that a non-DNA-binding protein might coordinately activate these factors by direct interaction with them. This model is based on precedent from studies of a number of viral immediate early regulatory factors. In particular, it has recently been demonstrated that the herpesvirus Vmw65 protein can interact specifically with OTF1 (Gerster and Roeder 1988), raising the possibility that an analogous cellular protein could be involved in cell-cycle control through interaction with the subtype-specific factors. The fact that the $\mathrm{H} 4, \mathrm{H} 2 \mathrm{~b}$, and $\mathrm{H} 1$ proximal subtype-specific elements are precisely positioned relative to the TATA box may suggest that such a putative regulatory factor could directly contact both a component of the initiation complex (TFIID?) and the subtype-specific factors. This type of model would explain the ability of OTF1 and H1TF1 to activate transcription upon entry into $S$ phase without coincident increases in their DNA binding activities. However, the observation that HITF2 DNA binding activity is increased during $S$ phase and that this does not result in a change in its migration in a mobility shift assay is less easily incorporated into this model.

A third possibility that we have considered is that a specific small molecule may interact noncovalently with these factors to activate transcription during $S$ phase. In this case, we imagine that such a molecule would be present (or, perhaps, absent) only during $S$ phase and that its availability could control the activity of the proposed S-phase-specific regulatory mechanism. Although no experimental data supporting this idea are presently available, there is ample precedent for this type of mechanism in the regulation of prokaryotic transcription and in the activation of a variety of receptors by specific ligands.

To discern whether these ideas pertain to the molecular mechanisms for activation of H1TF1, H1TF2, and OTF1 will require further in-depth analysis of these interesting proteins. These studies will be greatly facilitated by the preparation of specific antibodies to each of these factors and by utilization of the regulated cellcycle extracts described in this study.

\section{Materials and methods}

\section{Cell-culture and synchronization procedures}

HeLa cells were grown in suspension culture in minimal essential medium (Joklik) supplemented with $5 \%$ calf serum. Populations of HeLa cells homogeneously separated in different phases of the cell cycle were obtained by centrifugal elutriation (Meistrich et al. 1977; Lindahl 1986). In an average experiment, $3 \times 10^{9}$ to $4 \times 10^{9}$ cells were introduced into a $40-\mathrm{ml}$ chamber of a Beckman rotor JE 5.0, running at a speed of $3500 \mathrm{rpm}$ through a Masterflex peristaltic pump at a flow rate of $150 \mathrm{ml} /$ min. $G_{1}$ cells were floated out of the chamber by pumping in ice-cold phosphate-buffered saline (PBS) at a flow rate of 250 $\mathrm{ml} / \mathrm{min}$ flow rate. Cells at the $\mathrm{G}_{1} / \mathrm{S}$ boundary, in $\mathrm{S}$ phase, and in $\mathrm{G}_{2}$ phase were elutriated by slowly increasing the flow rate to 290,380 , and $450 \mathrm{ml} / \mathrm{min}$, respectively. At each step, $800 \mathrm{ml}$ of cells was collected on ice and an $800 \mu$ l aliquot of each fraction was mixed with $100 \mu \mathrm{l}$ of a $10 \%$ solution of Triton X-100 and $100 \mu \mathrm{l}$ of a $100 \mu \mathrm{g} / \mathrm{ml}$ solution of propidium iodide. Following a 10-min incubation at room temperature, 10,000 cells from each fraction were analyzed with a Becton Dickinson FACScan flow cytometer, using the Becton Dickinson Consort 30 program software. The remainder of the cells in each fraction were processed immediately for nuclear extracts, essentially as described previously (Heintz and Roeder 1984).

NIH-3T3 cells were maintained in Dulbecco's modified Eagle's medium (DMEM) supplemented with $10 \%$ fetal calf serum (FCS). Cells were plated at a density of $2 \times 10^{6} / 150-\mathrm{mm}$ petri dish, and a day later, the subconfluent monolayers were

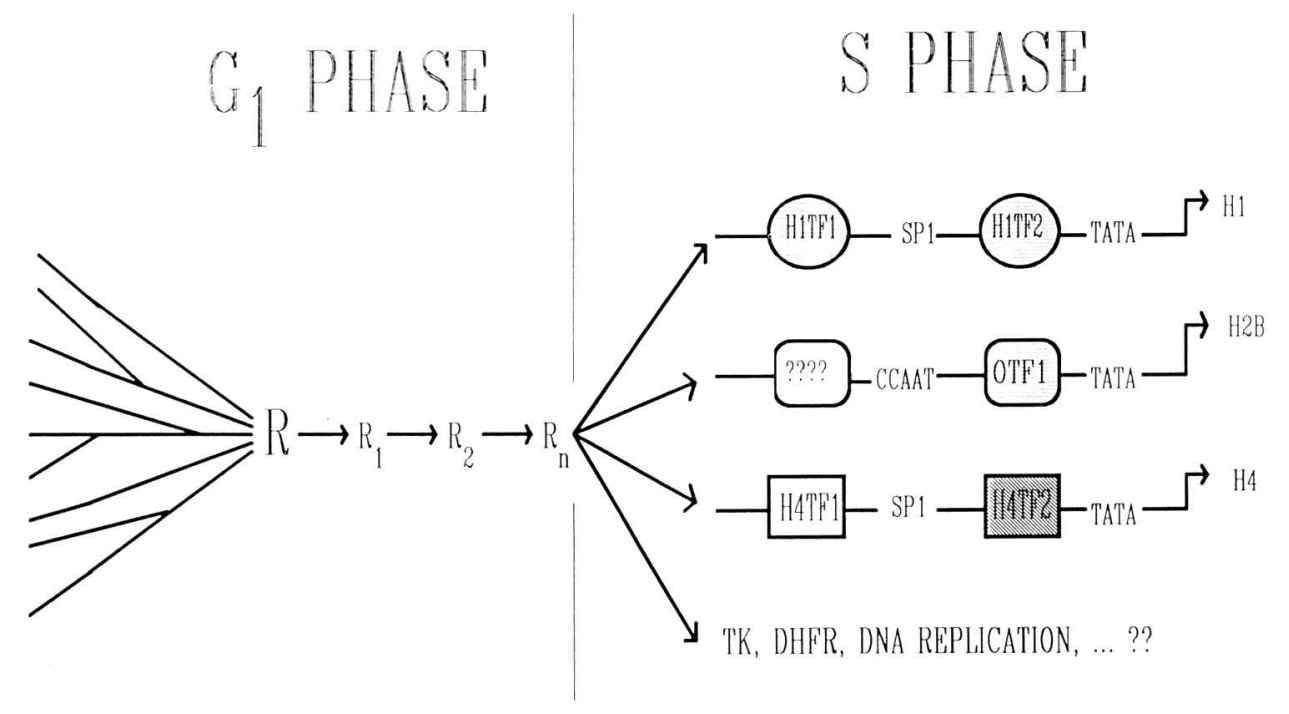

Figure 5. A model for histone gene regulation during the cell cycle. 
washed twice with PBS and the medium replaced with DME containing $0.5 \%$ FCS. Twenty-four to $30 \mathrm{hr}$ after serum starvation, cells were restimulated to grow with DME supplemented with $15 \%$ FCS. Two hours after serum stimulation, one-third of the culture was collected for nuclear extracts $(t=2)$, one-third was left undisturbed to progress through the cell cycle, and one-third was inhibited with $5 \mu \mathrm{g} / \mathrm{ml}$ aphidicolin (National Cancer Institute). At $t=18$, nuclear extracts were made from the two cultures grown in the absence or in the presence of aphidicolin. Cell synchronization was monitored routinely either by FACS analysis or by pulse-labeling cells with $10 \mu \mathrm{Ci} / \mathrm{ml}$ of $\left[{ }^{3} \mathrm{H}\right]$ thymidine (New England Nuclear) for $10 \mathrm{~min}$.

\section{In vitro transcription analysis}

Cell nuclear extracts were prepared essentially as described (Heintz and Roeder 1984). Protein concentration was measured by the Bradford method (Bradford 1976) and carefully adjusted among the synchronized cell extracts to $\sim 5 \mu \mathrm{g} / \mu \mathrm{l}$. The DNA templates and conditions used for in vitro transcription reactions, S1 analysis, gel electrophoresis, and densitometry were exactly as described previously (Gallinari et al. 1989).

\section{Gel shift analysis}

Gel shift assays were performed essentially as described (Fletcher et al. 1987; Gallinari et al. 1989), except that reaction mix for binding of HITFl contained $5 \%$ glycerol instead of $4 \%$ Ficoll.

\section{Acknowledgments}

We thank members of the Heintz laboratory for helpful discussion and advice. This work was supported by U.S. Public Health Service grant GM-32544 from the National Institutes of Health, a PEW Scholars Award (to N.H.) and the Howard Hughes Medical Institute.

\section{References}

Artishevsky, A., S. Wooden, A. Sharma, E. Resendez, and A. Lee. 1987. Cell cycle regulatory sequences in a hamster histone promoter and their interactions with cellular factors. Nature 328: 823-827.

Bradford, M.M. 1976. A rapid and sensitive method for quantitation of microgram quantities of protein utilizing the principle of protein-dye binding. Anal. Biochem. 72: 248-254.

Dailey, L., S.B. Roberts, and N. Heintz. 1988. Purification of the human histone $\mathrm{H} 4$ gene-specific transcription factors H4TF-1 and H4TF-2. Genes Dev. 2: 1700-1712.

Dailey, L., S.M. Hanly, R.G. Roeder, and N. Heintz. 1986. Distinct transcription factors bind specifically to two regions of the human histone H4 promoter. Proc. Natl. Acad. Sci. 83: $721-724$.

Dalton, S. and J.R.E. Wells. 1988a. A gene-specific promoter element is required for optimal expression of the histone $\mathrm{Hl}$ gene in S-phase. EMBO J. 7: 49-56.

- 1988b. Maximal binding levels of a H1 histone genespecific factor in S-phase correlate with maximal $\mathrm{Hl}$ gene transcription. Mol. Cell. Biol. 8: 4576-4578.

Fletcher, C., N. Heintz, and R.G. Roeder. 1987. Purification and characterization of OTF1, a transcription factor regulating cell cycle expression of a histone H2b gene. Cell 51: 773781.

Gallinari, P., F. La Bella, and N. Heintz. 1989. Characterization and purification of H1TF2, a novel CCAAT-binding protein that interacts with a histone $\mathrm{H} 1$ subtype specific consensus element. Mol. Cell. Biol. 9: 1566-1575.

Gerster, T. and R.G. Roeder. 1988. A herpesvirus transactivating protein interacts with transcription factor OTF1 and other cellular proteins. Proc. Nat1. Acad. Sci. 85: 63476351.

Hann, S.R., C.B. Thompson, and R.N. Eisenman. 1985. c-myc oncogene protein synthesis is independent of the cell cycle in human and avian cells. Nature 314: 366-369.

Heintz, N. and R.G. Roeder. 1984. Transcription of human histone genes in extracts from synchronized HeLa cells. Proc. Natl. Acad. Sci. 81: 2713-2717.

Heintz, N., H.L. Sive, and R.G. Roeder. 1983. Regulation of human histone gene expression: Kinetics of accumulation and changes in the rate of synthesis and half life of individual histone mRNAs during the HeLa cell cycle. Mol. Cell. Biol. 3: 539-550.

Ito, M., A. Sharma, A.S. Lee, and B. Maxson. 1989. Cell cycle regulation of $\mathrm{H} 2 \mathrm{~b}$ histone octamer DNA-binding activity in Chinese hamster lung fibroblasts. Mol. Cell. Biol. 9: 869873.

La Bella, F., H.L. Sive, R.G. Roeder, and N. Heintz. 1988. Cellcycle regulation of a human histone $\mathrm{H} 2 \mathrm{~b}$ gene is mediated by the $\mathrm{H} 2 \mathrm{~b}$ subtype-specific DNA consensus element Genes Dev. 2: 32-39.

Lee, M. and P. Nurse. 1988. Cell-cycle control genes in fission yeast and mammalian cells. Trends Genet. 4: 287-290.

Lindahl, P.E. 1986. On counter streaming centrifugation in the separation of cells and cell fragments. Biochim. Biophys. Acta 21: 411-415.

Meistrich, M.L., R.E. Meyn, and B. Barlogie. 1977. Synchronization of mouse L-P59 cells by centrifugal elutriation separation. Exp. Cell Res. 105: 169-177.

O'Neill, E.A., C. Fletcher, C.R. Burrow, N. Heintz, R.G. Roeder, and T.J. Kelly. 1988. Transcription factor OTF-1 is functionally identical to the adenovirus DNA replication factor NFIII. Science 241: 1210-1213.

Pledger, W.J., C.D. Stiles, H.N. Antoniades, and C.D. Scher. 1977. Induction of DNA synthesis in BALB/c3T3 cells by serum components: Reevaluation of the commitment process. Proc. Natl. Acad. Sci. 74: 4481-4485.

Robbins, E. and T.W. Borun. 1967. The cytoplasmic synthesis of histones in HeLa cells and its temporal relationship to DNA synthesis. Proc. Natl. Acad. Sci. 58: 1977-1983.

Sittman, D.B., R.A. Graves, and W.F. Marzluff. 1983. Histone mRNA concentrations are regulated at the level of transcription and mRNA degradation. Proc. Natl. Acad. Sci 80: $1849-1853$.

Zetterberg, A. and O. Larsson. 1985. Kinetic analysis of regulatory events in $G_{1}$ leading to proliferation or quiescence of Swiss 3 T3 cells. Proc. Natl. Acad. Sci. 82: 5365-5369. 


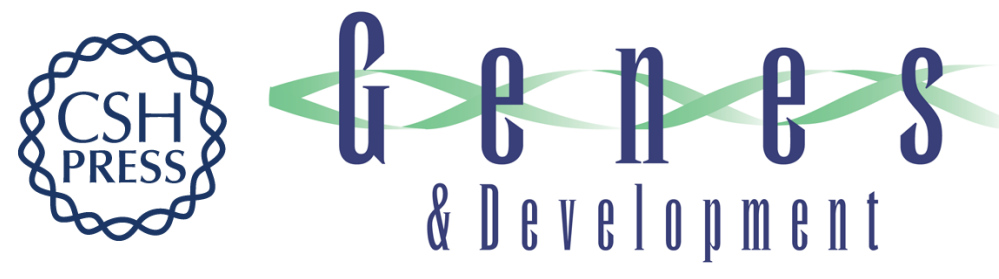

\section{Histone $\mathrm{H} 1$ subtype-specific consensus elements mediate cell cycle-regulated transcription in vitro.}

F La Bella, P Gallinari, J McKinney, et al.

Genes Dev. 1989, 3:

Access the most recent version at doi:10.1101/gad.3.12a.1982

References This article cites 22 articles, 13 of which can be accessed free at:

http://genesdev.cshlp.org/content/3/12a/1982.full.html\#ref-list-1

License

Email Alerting

Service

Receive free email alerts when new articles cite this article - sign up in the box at the top right corner of the article or click here.

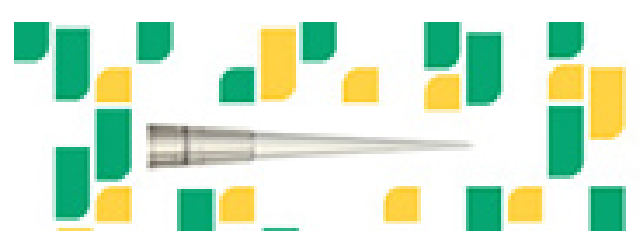

Focused on your science. 